\title{
The visible impacts of human activities constructing hydropower dam on Vietnamese Mekong Delta and conceptual solutions for responses
}

\author{
Nguyen Huu Nhan ${ }^{* a}$, Shigeko Haruyama ${ }^{b}$ \\ ${ }^{a}$ Vietnam Academy of Water Resources, nhan_vktb(at)yahoo.com \\ ${ }^{b}$ Mie university,haruyama(at)bio.mie-u.ac.jp \\ *corresponding author Nguyen Huu Nhan
}

Keywords: Environment, Visible mapping, Vietnamese Mekong delta, hydropower dams, Delta shrinking, Impact of human activities, conceptual solutions

\begin{abstract}
:
Regarding to the important environmental issues, eco-balance and eco-system should be discussed using long period data analysing and visible result of study. These visible results will be materials for construction of geo-design of the river basin. Both hydrological changes and surface changes of the Mekong delta was analysed with new data using hydrologic model with visible mapping in this study. The Mekong River delta, the third largest delta in the world, is presently shifting from growing to shrinking with its ecosystem and environment seriously degraded. These environmental changes are due to several factors such as 1)ill-planned water management schemes including hydropower dams in the river basin, 2) sediment starvation, 3) increased nutrient inflows, in combination with other human activities including infrastructural extension, riverbed mining, delta subsidence, degradation of coastal mangrove belt, and gaps in governance in the whole Mekong basin under the climate change and sea level rise. Both scientific and management communities have suggested that the rate of Mekong delta shrinking will increase markedly this century. The paper compiled new data and mapping together with recent key studies implying that much of the degradation in the Vietnamese Mekong delta is due to recent human activities, particularly hydropower dams in the entire Mekong river basin.

By comparison with period before 1990s when there were no large dams, the natural regime here has changed with the annual sediment load to the delta having decreased by $50-60 \%$, the flood discharges have also decreased, the hydrological seasonal regime has shifted as most of the Mekong River water is now trapped in these large dams, and the salinity intrusion into the delta now occurs earlier by 20-30 days. Further, the river bed is on the average deeper by 0.14 $\mathrm{m}$, to which riverbed mining also contributes. There has been a recent increase of erosion of river banks at 400 locations and coasts. The $66 \%$ of all of foreshore is now eroding, and the rate of these events is accelerating with time. If all the proposed mainstream hydropower dams in the Lower Mekong Basin have been built, then the Vietnamese Mekong delta with its ecosystems and about 18 million people face critical issues of sustainability. This presentation also focused on some remedial conceptual solutions that may decrease, but not eliminate, the negative impacts of these dams for the Vietnamese Mekong delta. Non-engineering solutions have the highest propriety, but engineering solutions are needed for protecting eroded coastal foreshore, river bank erosion and the fragile mangrove belt. Toward to realization of SDG's in this study region, the integrated management system of the river basin would be desired.
\end{abstract}

